\title{
The GARCH $(1,1)$ Model As A Risk Predictor For International Portfolios
}

Jean-François Laplante, Fonds de Solidarité du Québec, Canada

Jean Desrochers, Université de Sherbrooke, Canada

Jacques Préfontaine, Université de Sherbrooke, Canada

\begin{abstract}
This study pertains to forecasting portfolio risk using a GARCH (Generalized Autoregressive Conditional Heteroscedasticity) approach. Three models are compared to the GARCH model $(1,1)$ i.e., random walk $(R W)$, historical mean (HMM) and J.P. Morgan's exponentially weighted moving average (EWMA). In recent years, many volatility forecasting models have been presented in the financial literature. Using the historical average of stock returns to determine the optimal portfolio is current practice in academic circles. However, we doubt the ability of this method to provide the best estimated portfolio variance. Moreover, an error in the estimated covariance matrix could result in a completely different portfolio mix. Consequently, we believe it would be relevant to examine the volatility forecasting model proposed in different studies to estimate the standard deviation of an efficient portfolio. With a view to building an efficient portfolio in an international context, we will analyze the forecasting models mentioned above. The purpose of this research is to determine whether a GARCH approach to forecasting the covariance matrix makes it possible to obtain a risk that most resembles the actual observed risk for a given return than the model traditionally used by practitioners and academic researchers. To this end, we selected six international stock indices. The study was conducted in a Canadian context and consequently, each stock index is converted into Canadian dollars. Initially, we estimate the covariance matrix for each forecasting model mentioned above. Then, we determine the proportions to invest in the portfolio and calculate the standard deviation of a minimum variance portfolio. Finally, the best model is selected based on the variances between estimated and actual risk by minimizing the root mean squared error (RMSE) for each forecasting model. Our results show that the GARCH $(1,1)$ model is good for estimating risk in a minimum variance portfolio. As well, we find that it is statistically impossible to make a distinction between the accuracy of this model and the $R W$ model. Lastly, our results show that based on the four statistical error measures used, the HMM is the least accurate for estimating portfolio risk. We therefore decided not to use this model and to rely instead on the GARCH approach or the $R W$, the simplest of all the models.
\end{abstract}

Keywords: Currency Risk, Variance, Forecasting Model, GARCH, EWMA, Historical Mean, Random Walk.

\section{INTRODUCTION}

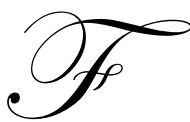

or many years, researchers were interested in forecasting financial asset returns. Today, their attention has shifted to forecasting return volatility. The major changes observed in stock market returns in recent years have awakened practitioners and researchers to the importance of risk management. Since then, many studies have been published and various risk measurement tools developed.

Volatility forecasting has many practical applications in the field of finance. Used in option evaluation models, volatility forecasting can also help determine the proportions to invest in a stock portfolio. In this paper, we focus more specifically on this latest topic of modern finance. 
Given that the volatility of the future returns of a financial asset, measured by the variance or standard deviation of the returns, is an essential component of portfolio selection, this measure must be as accurate as possible. Historical variance has been widely used to forecast the future variance of a financial asset. However, this measure does not take into account the trends that seem to exist in the time series under study. A good variance forecasting method must take into account the trends observed in time series. Consequently, it would be useful to examine the variability of the portfolio by using a variance forecasting model that takes into account past observations and past observed trends as in a GARCH approach.

\section{PROBLEM AND RESEARCH OBJECTIVE}

To minimize variance, it is important to have a good estimate of the variances and covariances of the portfolio's financial asset returns. Using forecasts that do not provide a reasonable estimate of variances and covariances close to their actual value can result in a portfolio mix that is totally different than would have been the case had the investors known the actual stock return variances and covariances. According to Chopra and Ziemba (1993), the composition of an efficient portfolio is extremely sensitive to estimation errors. Indeed, Chopra and Ziemba have shown that a slight change in estimating the parameters in Markowitz's mean variance model can result in a substantial variation in the composition of an efficient portfolio. Consequently, over- or under-estimating the covariance matrix in a portfolio minimization problem can result in substantial losses for investors. As such, resources must be used to obtain the best estimates possible of the covariance matrix as defined in the Markowitz model so as to obtain a better estimate, without however incurring marginal costs that exceed the marginal revenues generated.

According to West and Cho (1995) and Brailsford and Faff (1996), it appears that using the ARCH/GARCH model improves the capacity to forecast volatility. In fact, after examining different volatility forecasting models on the Australian stock index for a month, Brailsford and Faff concluded that GARCH $(1,1)$ and simple regression are the best volatility forecasting models.

Moreover, one of the main inputs in the Markowitz mean variance model is the covariance matrix. In this paper, we analyze the different forecasting models of this matrix. The purpose of this study is to forecast covariance matrices according to different forecasting models for international stock markets with a view to building an efficient portfolio for a Canadian investor within the framework of a mean variance model as defined by Markowitz.

To this end, we analyze four covariance matrix forecasting models, as follows: random walk (RW), historical mean (HMM), J.P. Morgan's exponentially weighted moving average (EWMA) and GARCH $(1,1)$.

For each model under study, we estimate a covariance matrix. Then, we determine the composition of the minimum variance portfolio (MVP) according to each forecasting model. Finally, we compare the standard deviation of the MVP to the one we would have estimated had we known the actual covariance matrix.

\section{LITERATURE REVIEW}

As shown by Harry Markowitz (1952-1958) and James Tobin (1959), diversification can reduce risk unless the assets are perfectly correlated. The theoretical portfolio selection model developed by Markowitz and Tobin provides an explanation for the diversification rules of risky assets. It bears mentioning that this model finds its application in a closed economy. Grubel (1968) was the first to apply the portfolio theory as defined by Markowitz and Tobin to an international context. Grubel showed that it was possible to reduce risk by holding a portfolio composed of international securities. The results obtained by Grubel were then supported by many authors. According to this research, for a given risk, the return will be higher on the international market than on the domestic market.

Before the work of Eun and Resnick (1984), no empirical research to determine the best method for estimating the correlation matrix in an international context had been conducted. These authors estimated twelve correlation matrix forecasting models. Alexander and Leigh (1997) studied three models currently used in the value 
at risk (VAR) model in order to forecast the covariance matrix. These authors concluded that the EWMA provides a better estimate of the risk measure than the GARCH models and equal mean squared returns.

\section{METHODOLOGY}

To forecast covariance matrices, we use daily information to ensure data independence in the time series. The study pertains to six international stock indices. The selected countries are Germany (DAX-100), Australia (ASX), Canada (TSE-300), the U.S. (S\&P 500), France (CAC-40), and Japan (Nikkei-225). The study covers the period from January 5, 1988 to December 31, 1997. In this study, we assume that the investor does not use foreign exchange risk hedging instruments. Table 1 presents a statistical description of the international indices.

Table 1

Statistical Description of Logarithmic Changes in Stock Indices

$r_{t}=\ln \left(I_{t} / I_{t-1}\right)$

Work Sample: January 5, 1988 to December 31, 1997

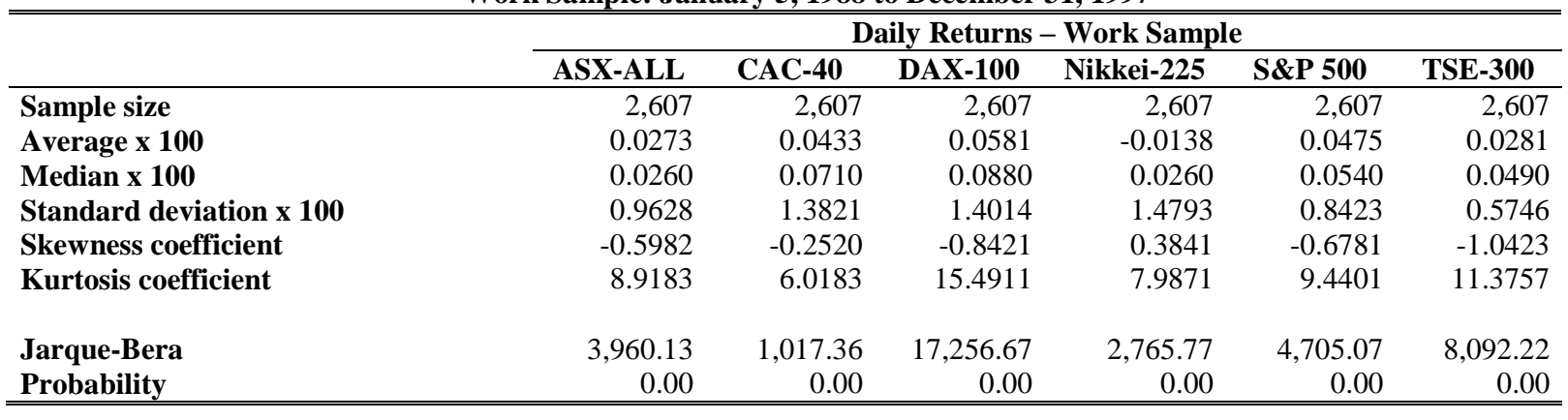

The results presented in Table 1 are consistent with those of other studies. In fact, an examination of the data reveals that the distributions are too leptokurtic and skewed to the left.

The daily return for each country, represented by the stock index, will be calculated as a continuous return.

Equation 1 Logarithmic change in a stock index

$$
r_{i(t)}=\ln \left(\mathbf{I}_{i(t)} / \mathbf{I}_{i(t-1)}\right)
$$

where $r_{i(t}$ is the daily return at time $\mathrm{t}$;

$I_{i(t)}$ is the value in Canadian dollars of the stock market index of country $i^{e}$ at the end of day $t$.

It should be noted that the return is calculated in Canadian dollars and that each stock market index will be adjusted to reflect all exchange rate changes during the period under study.

To ensure that the covariance matrix forecasting models only use data containing current information, and with a view to estimating the covariance matrix between the daily returns of the six selected countries, we calculated the variances and covariances between the return of each country according to the following equations:

Equation 2 Variance calculation

$$
\sigma_{\mathrm{i}(\mathrm{t})}^{2}=\sum_{\mathrm{t}=1}^{N_{\mathrm{T}}}\left(\boldsymbol{r}_{i(t)}-\mathrm{E}\left(\boldsymbol{r}_{i}\right)\right)^{2}
$$




\section{Equation 3 Covariance calculation}

$$
\sigma_{i j(t)}=\sum_{t=1}^{N_{\mathrm{T}}}\left(r_{i(t)}-\mathrm{E}\left(r_{i}\right)\right)\left(r_{j(t)}-\mathrm{E}\left(r_{j}\right)\right)
$$

where $r_{i(t)}$ and $r_{j(t)}$ are the daily returns of countries $i^{\mathrm{e}}$ and $j^{\mathrm{e}}$ defined in equation $1, \mathrm{E}\left(r_{i}\right)$ and $\mathrm{E}\left(r_{j}\right)$ are the average daily returns and we assume that $\mathrm{E}\left(r_{i}\right)$ and $\mathrm{E}\left(r_{j}\right)$ are equal to zero and $N_{\mathrm{T}}$ is the number of transaction days in month $\mathrm{t}$.

Since the purpose of this research is to determine the covariance matrix forecasting model that minimizes errors between forecasted and observed risk, we broke down our sample into two equal parts. The first part (January 1988 to December 1992) is used to estimate the parameters of the covariance matrix forecasting model. Then, we apply these parameters to the second part of our sample (January 1993 to December 1997) for testing. Parameter estimates are made over a constant period of 60 months. As well, the parameters are estimated again for each subsequent month. We assume that the portfolio managers review their position every month. As such, the first covariance matrix forecast is obtained for January 1993. Each subsequent forecast is established on a monthly basis until December 1997. For each forecast, we compare the standard deviation of the minimum variance portfolio obtained with each covariance matrix forecasting model to the one that would have been obtained had we known the actual variances and covariances of each index.

In order to compare the portfolios obtained according to the different covariance matrix forecasting models with the portfolio that would have been selected had the real stock variances and covariances been known, we define the actual asset variances and covariances for a one-month period as follows:

The asset variances and covariances, had they been known at the time of the forecast, would be as follows:

\section{Equation $4 \quad$ Actual variance}

$$
\sigma_{\mathrm{i}(\mathrm{t})}^{2}=\sum_{\mathrm{t}=-1}^{N_{\mathrm{T}}} r_{i,(t)}{ }^{2}
$$

Equation 5 Actual covariance

$$
\sigma_{i j(t)}=\sum_{t=-1}^{N_{\mathrm{T}}} \boldsymbol{r}_{i(t)} \boldsymbol{r}_{j(t)}
$$

where $\quad r_{i}$ and $r_{j}$ are the daily returns and $N_{\mathrm{T}}$ is the number of transaction days in month $\mathrm{t}$ following the forecast. This is an ex post measure because we will measure the variances and covariances actually observed.

In order to build an efficient portfolio, we assume that short-selling and margin buying are not allowed and that it is impossible to lend and borrow at the same interest rate without risk. The assumption under which shortselling and margin buying are not permitted is consistent with the economic environment observed in some countries. However, in industrialized countries, these practices are allowed with certain conditions that eliminate the advantages. Consequently, the function that we will seek to minimize will be:

\section{Equation 6 Portfolio variance minimization model under constraints}

$$
\text { Minimize } \sum_{i=1}^{N} X_{i}^{2} \sigma_{i}^{2}+\sum_{i=1}^{N} \sum_{\substack{j=1 \\ j \neq i}}^{N} X_{i} X_{j} \sigma_{i j}
$$


Under constraint:

$$
\begin{aligned}
& \sum_{i=1}^{N} X_{i}=1 \\
& \sum_{i=1}^{N} X_{i} \mathrm{E}\left(r_{i}\right)=\mathrm{E}(\mathrm{Rp}) \\
& X_{i} \geq 0, \quad i=1, \ldots, N \\
& X_{i} \leq 1, \quad i=1, \ldots, N
\end{aligned}
$$

In the next section, we present the different models used to forecast variances and covariances of selected stock indices with a view to determining the covariance matrix. We selected models that are widely used in the financial literature.

\subsection{Variance And Covariance Forecasting Models}

\subsubsection{Random Walk Model}

According to the random walk model (RW), the best forecast of future variances and covariances are the variances and covariances observed during the current period. ${ }^{1}$

\section{Equation 7 Monthly variance forecast according to RW}

$$
\hat{\sigma}_{\mathrm{i}(\mathrm{t}+1)}^{2}(R W)=\sigma_{\mathrm{i}(\mathrm{t})}^{2}+\varepsilon_{\mathrm{i}(\mathrm{t}+1)}
$$

\section{Equation 8 Monthly covariance forecast according to RW}

$$
\hat{\sigma}_{\mathrm{ij}(\mathrm{t}+1)}(R W)=\sigma_{\mathrm{ij}(\mathrm{t})}+\varepsilon_{(\mathrm{t}+1)}
$$

where $\quad \sigma_{\mathrm{i}(\mathrm{t})}^{2} \sigma_{\mathrm{ij}(\mathrm{t})}$ are the variance and covariance measures according to the forecasting horizon defined in equations 4 and 5 , respectively.

\subsubsection{Historical Mean Model (HMM)}

According to the hypothesis of a mean and stationary variance, the best variance and covariance forecasts based on the forecast horizon are the medium to long-term variances and covariances observed in the past.

1 To simplify the equations, the symbol $\left[\left.\right|_{(t-1)}\right]$ (given that we know the information at time t-1) does not appear in the equations. 
Equation 9 Monthly variance forecast according to HMM

$$
\hat{\sigma}_{i(t+1)}^{2}(H M M)=\frac{1}{60-1} \sum_{t=0}^{-59}\left(r_{i(t)}-E\left(r_{i}\right)\right)^{2}
$$

Equation 10 Monthly covariance forecast according to HMM

$$
\hat{\sigma}_{i j(t+1)}(H M M)=\frac{1}{60-1} \sum_{t=0}^{-59}\left(\boldsymbol{r}_{i(t)}-E\left(\boldsymbol{r}_{i}\right)\right)\left(\boldsymbol{r}_{j(t)}-E\left(\boldsymbol{r}_{j}\right)\right)
$$

where $r_{i(t)}$ is the monthly index return $i, \mathrm{E}\left(r_{i}\right)$ is the mean monthly return.

As you can see, this model does not take into account the evolution of the volatility and assigns each observation the same importance regardless of when they occur in time. We calculate the variances and covariances over a 60 -month period using monthly data.

\subsubsection{J.P. Morgan EWMA Model (RiskMetrics ${ }^{T M}$ )}

Based on the work of J.P. Morgan and Reuters (1996), we examine the EWMA model. To forecast variances and covariances, we use the J.P. Morgan and Reuters (1996) methodology proposed in RiskMetrics ${ }^{\mathrm{TM}}$.

\section{Equation 11 Monthly variance forecast according to EWMA}

$$
\hat{\sigma}_{i(t+1)}^{2}(E W M A)=\lambda \hat{\sigma}_{i(t)}^{2}+(1-\lambda) r_{i(t+1)}^{2}
$$

\section{Equation 12 Daily covariance forecast according to EWMA}

$$
\hat{\sigma}_{i, j(t+1)}(E W M A)=\lambda \hat{\sigma}_{i, j(t)}+(1-\lambda) \boldsymbol{r}_{i(t+1)} \times \boldsymbol{r}_{j(t+1)}
$$

where $\sigma_{i(t)}^{2}$ and $\sigma_{i, j(t)}$ represent the estimated daily variance and covariance of the last period and $\lambda$ is the J.P. Morgan decreasing factor which is defined as having a value of 0.97 as proposed in RiskMetrics ${ }^{\mathrm{TM}}$ for monthly forecasting. The decreasing factor determines the relative weight assigned to observations as well as the number of data used to estimate volatility. We used 550 daily returns to construct the forecasts.

To forecast monthly variances and covariances, the J.P. Morgan methodology involves multiplying the variance or covariance by the number of days in the month. J.P. Morgan assumes 25 as the constant number of days for each month. Consequently, the covariance and variance forecasts are defined as follows:

\section{Equation 13 Monthly variance forecast according to EWMA}

$$
\hat{\sigma}_{i(t, 25)}^{2}(E W M A)=\sigma_{i,(t+1)}^{2} \times 25
$$

\section{Equation 14 Monthly covariance forecast according to EWMA}

$$
\hat{\sigma}_{i, j(t, 25)}(E W M A)=\sigma_{i, j(t+1)} \times 25
$$




\subsubsection{GARCH Model $(1,1)$}

According to Akgiray (1989), Baillie and DeGennaro (1990) and Lamoureux and Lestrapes (1990), the GARCH model is generally the best choice for predicting stock returns. We use the methodology of Brailsford and Faff (1996) to estimate the GARCH $(1,1)$ model parameters as well as to establish the volatility forecast according to the different forecast horizons. The GARCH model $(1,1)$ is estimated using the maximum likelihood technique.

\section{Equation 15 Return-generating model}

$$
\mathbf{r}_{(\mathrm{t}+1)}=\delta+\mathcal{E}_{(\mathrm{t}+1)}
$$

where $\delta$ is an ARMA process $(\mathrm{p}, \mathrm{q}), \mathrm{p}, \mathrm{q}=(0,1, \ldots, 5)$ and $\varepsilon_{\mathrm{t}+1} \sim \mathrm{N}\left(0, h_{\mathrm{t}+1}\right)$ and $h_{\mathrm{t}+1}$ is represented by equation 16 .

Equation 16 Conditional variance

$$
h_{(\mathrm{t}+1)}=\varpi+\beta_{1} h_{(\mathrm{t})}+\alpha_{1} \varepsilon_{(\mathrm{t})}^{2}
$$

where $h_{\mathrm{t}}$ represents the conditional variance used to take into account the volatility change of the error term stemming from the conditional mean.

Equation 17 Daily conditional variance forecast

$$
\hat{h}_{t+s}(G A R C H)=\hat{\omega} \sum_{i=0}^{s-2}\left(\hat{\alpha}_{1}+\hat{\beta}_{1}\right)^{i}+\left(\hat{\alpha}_{1}+\hat{\beta}_{1}\right)^{s-1} \hat{h}_{t+1}
$$

where $s=\left(1,2, \ldots, \mathrm{N}_{\mathrm{T}}\right)$ and $\mathrm{h}_{\mathrm{t}+1}$ represents the day following the volatility forecast for the first day of each month generated by the result of equation 16 .

\section{Equation 18 Monthly variance forecast according to GARCH $(1,1)$}

$$
\hat{\sigma}_{\mathrm{t}}^{2}(G A R C H)=\sum_{\mathrm{s}=1}^{\mathrm{N} t} \hat{h}_{\mathrm{t}+\mathrm{s}}(G A R C H)
$$

The variance forecast using GARCH $(1,1)$ is given according to the following equation:

Equation 19 Monthly variance forecast according to GARCH $(1,1)$

$$
\hat{\sigma}_{\mathrm{t}}^{2}(G A R C H[1,1])=\hat{\omega} \sum_{\mathrm{s}=1}^{\mathrm{N} t} \sum_{\mathrm{i}=0}^{\mathrm{s}-2}\left(\hat{\alpha}_{1}+\hat{\beta}_{1}\right)^{i}+\sum_{\mathrm{s}=1}^{\mathrm{N} t}\left(\hat{\alpha}_{1}+\hat{\beta}_{1}\right)^{s-1} \hat{h}_{\mathrm{t}+1}
$$

To forecast covariances between stock indices, we use the monthly correlation coefficient. As such, covariance forecasting is simply the product of estimated conditional standard deviations using a GARCH $(1,1)$ approach times the monthly correlation coefficient. This procedure assumes that the correlation coefficient is constant over time. 


\section{Equation 20 Monthly covariance forecast}

$$
\hat{h}_{i, j(t+1)}=\sqrt{\hat{h}_{i(t)}} \sqrt{\hat{h}_{j(t)}} \rho_{i j,(t)}
$$

where $\rho_{i j,(t)}$ is the monthly correlation coefficient between stock $i^{\mathrm{e}}$ and $j^{\mathrm{e}}$ and $h_{i(t)}$ is the conditional variance of stock $\mathrm{i}^{\mathrm{e}}$.

\subsection{Definition Of Statistical Errors}

The forecast errors generated for the 60 forecasts according to each model analyzed are compared using mean error (ME), mean absolute error (MAE), root mean squared error (RMSE) and mean absolute percent error (MAPE). The statistical error measures are presented in the appendix.

\section{RESULTS}

In order to compare the risk estimated by the forecast models of the covariance matrix to the risk actually observed, we analyze the different statistical error measures between the estimated standard deviations of the MVP portfolio and the actual standard deviations observed in this portfolio. Figure 1 presents the estimated and actual standard deviations of the MVP for the 60 months in the forecast. As well, Table 2 presents the actual and relative forecast errors as well as the standard deviations of the four models analyzed according to the four error measures.

An analysis of Table 2 shows that no model is actually better than the next. The ME measure does not allow us to draw conclusions as to the accuracy of the model because the errors can cancel themselves out depending on the different equation signs. We therefore do not place great importance on this measure except to indicate as to whether the models tend to over- or underestimate MVP volatility. Based on our results, all the models, except for the random walk, tend to overestimate the standard deviation of the MVP,

Figure 1

Standard Deviation Forecast of a Minimum Variance Portfolio

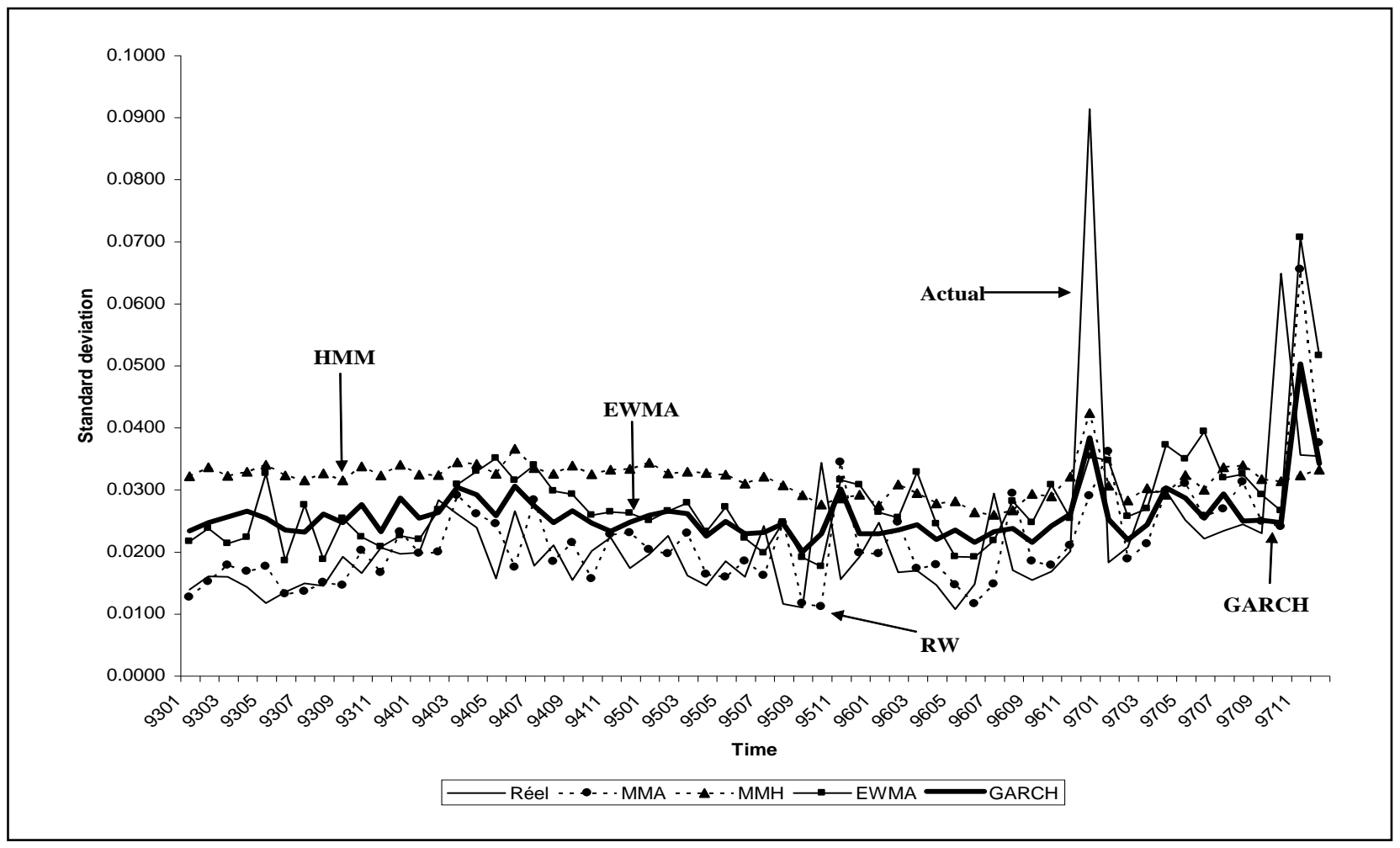


Table 2

Analysis of Statistical Error Measures

of Estimated Risk in Relation to Actual Risk of the MVP

Portfolio Based on Different Statistical Error Measures

\begin{tabular}{|c|c|c|c|c|c|c|c|}
\hline \multirow[b]{3}{*}{ Models } & \multicolumn{7}{|c|}{ STATISTICAL ERRORS } \\
\hline & \multirow{2}{*}{$\begin{array}{c}\text { ME } \\
\text { Actual }\end{array}$} & \multicolumn{2}{|c|}{ MAE } & \multicolumn{2}{|c|}{ RMSE } & \multicolumn{2}{|c|}{ MAPE } \\
\hline & & Actual & Relative & Actual & Relative & Actual & Relative \\
\hline RW & $\begin{array}{c}-0.000095 \\
(0.012503)\end{array}$ & $\begin{array}{c}0.006902 \\
(0.010387)\end{array}$ & 0.525292 & $\begin{array}{c}0.012399 \\
(0.000552)\end{array}$ & 0.823579 & $\begin{array}{c}0.284225 \\
(0.280831)\end{array}$ & 0.390608 \\
\hline HMM & $\begin{array}{c}0.009849 \\
(0.011483)\end{array}$ & $\begin{array}{c}0.013140 \\
(0.007411)\end{array}$ & 1.000000 & $\begin{array}{c}0.015055 \\
(0.000331)\end{array}$ & 1.000000 & $\begin{array}{c}0.727649 \\
(0.446363)\end{array}$ & 1.000000 \\
\hline EWMA & $\begin{array}{c}0.006164 \\
(0.012451)\end{array}$ & $\begin{array}{c}0.010396 \\
(0.009151)\end{array}$ & 0.791208 & $\begin{array}{c}0.013800 \\
(0.000458)\end{array}$ & 0.916594 & $\begin{array}{c}0.508935 \\
(0.338180)\end{array}$ & 0.699424 \\
\hline $\operatorname{GARCH}(1,1)$ & $\begin{array}{c}0.004071 \\
(0.010828)\end{array}$ & $\begin{array}{c}0.008132 \\
(0.008176)\end{array}$ & 0.618863 & $\begin{array}{c}0.011483 \\
(0.000408)\end{array}$ & 0.762731 & $\begin{array}{c}0.415063 \\
(0.295194)\end{array}$ & 0.570416 \\
\hline
\end{tabular}

Note: The values in brackets indicate the standard deviation of the forecast error.

According to the MAE statistic, the random walk model provides the best forecast, i.e., $47 \%$ more accurate than the HMM. The GARCH $(1,1)$ model ranks second, providing a forecast that is $38 \%$ more accurate than the HMM. However, the standard deviation of the GARCH $(1,1)$ model $(0.0082)$ is less than the standard deviation of the RW (0.0104). This means that if these two models are used to forecast risk, the chance of error is lower with GARCH $(1,1)$.

On the other hand, according to the RMSE statistic, the GARCH $(1,1)$ model comes out ahead of the RW, which is slightly more reliable than the HMM and the EWMA. The GARCH $(1,1)$ is $24 \%$ more accurate than the HMM, RW and EWMA which are $18 \%$ and $8 \%$ respectively more accurate than the HMM. It bears mentioning that this error measure penalizes deviation over the average more harshly than the MAE. Consequently, we place more importance on the RMSE statistic than the MAE in choosing the best covariance matrix forecasting model.

Lastly, the MAPE statistic provides a relative indication of all the forecast performance measures. According to this statistical error measure, the RW provides the smallest MAPE with $28.42 \%$ (actual). The GARCH $(1,1)$ ranks second with an MAPE of $41.51 \%$ (actual), which is approximately twice the MAPE of the RW. With an MAPE of $72.76 \%$ (actual), the HMM once again performed poorly. In fact, the RW, the GARCH $(1,1)$ and the EWMA are $61 \%, 43 \%$ and $30 \%$ respectively more accurate than the HMM.

In summary, selecting the best forecasting model depends on the statistical error measures used. However, it is clear from this analysis that the HMM is the worst model for forecasting the covariance matrix.

We also estimated the risk incurred by the investor if he were to buy the MVP portfolio according to each model. As such, if an investor decided to use a naive model to estimate the proportions to invest in an MVP portfolio, what risk would he have effectively incurred by taking into account the actual covariance matrix obtained in the following month? The results are presented in Table 3 as follows:

Based on the statistics, the naive forecast model is the one that minimizes portfolio risk if the investor has invested according to the results obtained. Based on the RMSE statistic, the GARCH model ranks second, followed closely by the historical model. The other statistics also confirm this observation.

A surprising result is that using the EWMA model causes the investor to take on more risk, more on average than the forecast based on the historical model, which ranked last when we measured forecast errors only.

We will have to continue this study with individual stock portfolios in order to check whether these rather sophisticated forecasting models are more useful than their simpler counterparts when portfolios of varying sizes are used. 
Table 3

Analysis of Statistical Error Measures of Estimated Risk in Relation to Actual Risk Of the MVP Portfolio Based on Different Statistical Error Measures

\begin{tabular}{|c|c|c|c|c|c|c|c|}
\hline \multirow[b]{3}{*}{ Models } & \multicolumn{7}{|c|}{ "STATISTICAL ERRORS } \\
\hline & \multirow{2}{*}{$\begin{array}{c}\text { ME } \\
\text { Actual }\end{array}$} & \multicolumn{2}{|c|}{ MAE } & \multicolumn{2}{|c|}{ RMSE } & \multicolumn{2}{|c|}{ MAPE } \\
\hline & & Actual & Relative & Actual & Relative & Actual & Relative \\
\hline RW & 0.001838 & 0.003306 & 0.631359 & 0.006549 & 0.784141 & 0.147697 & 0.582236 \\
\hline & $(0.006338)$ & $(0.005700)$ & & $(0.000249)$ & & $(0.120810)$ & \\
\hline HMM & $\begin{array}{c}0.002671 \\
(0.006837)\end{array}$ & $\begin{array}{c}0.004139 \\
(0.006048)\end{array}$ & 0.790450 & $\begin{array}{c}0.007287 \\
(0.000250)\end{array}$ & 0.872579 & $\begin{array}{c}0.179452 \\
(0.156495)\end{array}$ & 0.707416 \\
\hline EWMA & $\begin{array}{c}0.003768 \\
(0.007516)\end{array}$ & $\begin{array}{c}0.005236 \\
0.006561)\end{array}$ & 1.000000 & $\begin{array}{c}0.008351 \\
(0.000252)\end{array}$ & 1.000000 & $\begin{array}{c}0.253672 \\
(0.267764)\end{array}$ & 1.000000 \\
\hline GARCH $(1,1)$ & $\begin{array}{c}0.002173 \\
(0.006773)\end{array}$ & $\begin{array}{c}0.003641 \\
(0.006098)\end{array}$ & 0.695273 & $\begin{array}{c}0.007059 \\
(0.000251)\end{array}$ & 0.845234 & $\begin{array}{c}0.162060 \\
(0.638856)\end{array}$ & 0.638856 \\
\hline
\end{tabular}

Note: $\quad$ The values in brackets indicate the standard deviation of the forecast error.

\section{CONCLUSION}

In this paper, we analyzed errors in forecasting the standard deviation of minimum variance portfolios. Different models were studied: random walk, historical mean, exponentially weighted moving average and GARCH $(1,1)$.

We began by defining the problem under study. We then described the data required for this research, followed by a description of the methodology used to forecast a covariance matrix according to different models and the statistical measures used to evaluate forecasting errors. Lastly, we presented the results of the study.

We concluded that GARCH $(1,1)$ is a good model for forecasting the covariance matrix for a one-month investment horizon. However, we cannot unequivocally determine which covariance matrix forecasting model is better, random walk or GARCH $(1,1)$. However, it does seem that the covariance matrix forecast obtained with GARCH $(1,1)$ is superior to the historical mean model. Consequently, it would appear that GARCH $(1,1)$ rather than the historical mean model should be used to estimate the risk of an optimal portfolio. In light of its low cost, the random walk model could also be contemplated. Moreover, the risk incurred by using the naive model is lower. What is surprising is that although the historical model is rejected for testing forecasting errors, it is useful for analyzing risk.

\section{AUTHOR INFORMATION}

Jacques Préfontaine is professor of finance at Université de Sherbrooke P.Q. Canada where he presently holds the position of Desjardins Chair in sustainable development. He obtained a Ph.D. in finance from the University of Western Ontario. Jacques teaches financial institution and alternative investment management courses both at the undergraduate and graduate levels. His research interests and publications center on corporate social responsibility, risk management financial disclosure and market discipline. He is also active as a board member or as a consultant to several public and private sector organizations.

Jean Desrochers is professor of finance at Université de Sherbrooke P.Q. Canada where he presently holds the position of director of the Venture capital research group. He obtained a Ph.D. in finance from the University Laval, Québec, Canada. Jean teaches financial institution and Portfolio theory at the undergraduate and graduate level. His research interests and publications center on venture capital, risk management financial disclosure and market efficiency. He is also active as a board member or as a consultant to several public and private sector organizations.

Jean-François Laplante is a securities analyst advisor with Fonds de solidarité FTQ. He has more than 10 years of investment experience. Prior to joining Fonds de solidarité FTQ, Jean-François worked with one of Canada's largest independent investment dealer as an associtate. He was also an advisor at CDP Capital where he actively participated in the creation of a venture capital fund of funds. He also held analyst positions with CIBC Asset 
Management (formerly TAL) and AXA Canada. Jean-François holds a B.Sc. and a M. Sc. in Finance from the Université de Sherbrooke and he also holds the Chartered Financial Analyst (CFA) designation.

\section{BIBLIOGRAPHY}

1. Akgiray, V., "Conditional Heteroscedasticity in Time Series of Stock Returns: Evidence and Forecasts," Journal of Business, 62, 1989, p. 55-80.

2. Alexander, C.O., Leigh, C.T., "On the Covariance Matrices Used in Value at Risk Models," The Journal of Derivatives, (Sring 1997), p. 50-62.

3. Baillie, R.T. and DeGennaro, R.P. "Stock Returns and Volatility," Journal of Finance and Quantitative Analysis, (1990), p. 203-214.

4. Boudoukh, Jacob and all, "Investigation of Class of Volatility Estimators," Journal of Derivatives, Vol. 4, No. 3, (Spring 1997), p. 63-71.

5. Brailsford, Timothy J., FAFF, Robert W., "An Evaluation of Volatility Forecasting Techniques,” Journal of Banking \& Finance, Vol. 20, No. 3, (April 1996), p. 419-438.

6. Chopra, Vijay K., Ziemba, William T., "The Effect of Errors in Means, Variances, and Covariances on Optimal Portfolio Choice," The Journal of Portfolio Management, (Winter 1993), p. 6-11.

7. Elton, Edwin J., Gruber, Martin J., Modern Portfolio Theory and Investment Analysis, John Wiley \& Sons, New York, (1995), 715 p.

8. $\quad$ Enders, Walter, Applied Econometric Time Series, John Wiley \& Sons, New York, (1995), 433 p.

9. Eun, Cheol, Resnick, Bruce G. "Estimating the Correlation Structure of International Share Prices," The Journal of Finance, Vol. 39, No. 5, (December 1984), p. 1311-1324.

10. Figlewski, Stephen, "Forecasting Volatility," Financial Markets, Institutions \& Instruments, Vol. 6, No. 1, (1997), p. 1-88.

11. Frankfuther, George M. and Lamoureux, Christopher G., "Estimation and Selection Bias in MeanVariance Portfolio Selection,” Journal of Financial Research, Vol. 12, No. 2, (Summer 1989), p. 173-182.

12. French, K.R., Schwert, W., and Stambaugh, R. F., "Expected Stock Returns and Volatility," Journal of Financial Economics, (1987), p. 3-29.

13. Grubel, Herbert G., Kenneth Fadner, "The Interdependance of International Equity Markets," Journal of Finance, p.89-94.

14. Hatch, James E., "Investment Management in Canada," 2nd Edition, Prentice Hall, Scarborough, 1989, $836 \mathrm{p}$.

15. J.P. Morgan and Reuters, RiskMetrics ${ }^{T M}$-Technical Document, 4th Edition, New York, (December 1996), $283 \mathrm{p}$.

16. Lamoureux, C.G., W.D. Lestrapes, "Persistence in Variance, Structure Change, and the GARCH Model," Journal of Business and Economic Statistics, 1990, p. 225-234.

17. Markowitz, Harry, "Portfolio Selection," The Journal of Finance, (1952), p. 77-91.

18. Schwert, William G., "Why Does Stock Market Volatility Change Over Time?" The Journal of Finance, Vol. 64, No. 5, (December 1989), p. 1115-1153.

19. Schwert, William G., Seguin, Paul J., "Heteroskedasticity in Stock Returns," The Journal of Finance, (September 1990), p. 1129-1155.

20. Solnik, Bruno, Boucrelle, Cyril and LE FUR, Yann, "International Market Correlation and Volatility," Financial Analysts Journal, (September/October 1996), p. 17-34.

21. West, Kenneth D., Cho, Dougchul, "The Predictive Ability of Several Models of Exchange Rate Volatility," Journal of Econometrics, Vol. 69, (1995), p. 367-391. 


\section{APPENDIX: STATISTICAL ERROR MEASURES}

\section{Equation 21}

$$
M E=\frac{1}{60} \sum_{\mathrm{t}=1}^{60}\left(\hat{\sigma}_{\mathrm{pt}}^{2}-\sigma_{\mathrm{pt}}^{2}\right)
$$

Equation 22

$$
M A E=\frac{1}{60} \sum_{\mathrm{t}=1}^{60}\left|\hat{\sigma}_{\mathrm{pt}}^{2}-\sigma_{\mathrm{pt}}^{2}\right|
$$

Equation 23

Equation 24

$$
R M S E=\sqrt{\frac{1}{60} \sum_{\mathrm{t}=1}^{60}\left(\hat{\sigma}_{\mathrm{pt}}^{2}-\sigma_{\mathrm{pt}}^{2}\right)^{2}}
$$

$$
M A P E=\frac{1}{60} \sum_{\mathrm{t}=1}^{60}\left|\left(\hat{\sigma}_{\mathrm{pt}}^{2}-\sigma_{\mathrm{pt}}^{2}\right) / \sigma_{\mathrm{pt}}^{2}\right|
$$

where $\sigma_{\mathrm{pt}}^{2}$ is the actual portfolio variance that would have been observed if it had been known by investors and $\hat{\sigma}_{\mathrm{pt}}^{2}$ is the portfolio variance estimated with the covariance matrix forecasting models. 